\title{
Brokering a settlement between eagles and industry: sustainable management of large raptors nesting on power infrastructure
}

\author{
ANDREW R. JENKINS, KOOS H. DE GOEDE, LOVELATER SEBELE and \\ MEGAN DIAMOND
}

\section{Summary}

In the Karoo region of South Africa, eagles nesting on high voltage power pylons are responsible for frequent short-circuits or faults, which reduce the quality of commercial power supply and escalate costs to the country's energy supplier, Eskom. Between 2002 and 2006 we conducted annual helicopter surveys of eagle nests on 1,400 km of power line and located 139 large nest structures, making up 96 eagle territories occupied by three species: Martial Eagle Polemaetus bellicosus (66 pairs), Verreaux's Eagle Aquila verreauxii (13 pairs) and Tawny Eagle Aquila rapax ( 17 pairs), and detailed 357 pair-years of breeding activity, including 241 breeding attempts. Roost sites and active nests were associated with line faulting, and more so at particular pylon configurations. We developed a three-step management plan to reduce eagle-related faulting while still accommodating eagles on the power lines: (i) all (potentially) problematic nests were relocated from high-risk positions above the power conductors, to specially provided platforms placed below the conductors; (ii) perch deterrents were installed above the conductors on all nest pylons and on high-risk pylons up to 10 structures on both sides of each nest tower; and (iii) the welfare of the eagles was monitored before and after management. In this way, line faulting was reduced on actively managed lines by $>75 \%$, with no obvious deleterious effects on the eagle population. The study revealed that: (i) power lines can support substantial breeding populations of threatened large raptors, (ii) these birds can be a source of commercially significant line faulting, and (iii) nest relocations and perch deterrents are effective in reducing faulting without negatively impacting eagle populations.

\section{Introduction}

Large eagles are apex predators, which occur at naturally low densities and reproduce slowly (Newton 1979). These limiting qualities are often exacerbated by a range of anthropogenic impacts, to the extent that many of the world's populations of large eagles are under threat (e.g. Carrete et al. 2002, González et al. 2007, Ryabatsev and Katzner 2007, Whitfield et al. 2007). Sub-Saharan Africa supports a diverse eagle fauna, including as many as eight genuinely large (regularly $>2 \mathrm{~kg}$ in body mass), resident species from several genera (del Hoyo et al. 1994, Ferguson-Lees and Christie 2001). In keeping with global trends, most of these birds are considered threatened in at least part of their respective African ranges, and many only attain significant numbers within the continent's dwindling network of protected areas (Virani and Watson 1998; Herremans and Herremans-Tonnoeyr 2000, Thiollay 2007). In this context, situations where eagles or any form of threatened wildlife are able to benefit from human effects on the environment are potentially significant in affecting the long-term survival of these taxa 
(Marzluff et al. 2001, McKinney 2002, Rutz 2008), and especially so where benefit is derived from key components of inevitable and ongoing industrial development.

Such a situation presently obtains in the semi-arid Karoo region of central and south-western South Africa, where steel lattice towers supporting medium and high voltage power lines have been adopted as a nesting substrate by three large eagle species. This phenomenon was first observed in the area in the 1970s, when a pair of Martial Eagles Polemaetus bellicosus was recorded nesting on a power pylon in the central Karoo about three years after the corresponding power line was erected (Dean 1975). Pylon nesting has since spread widely throughout the Karoo, particularly in Martial Eagle, but also in Verreaux's Eagle Aquila verreauxii and Tawny Eagle A. rapax (Simmons 2005a,b,c). Given that both Martial Eagle and Tawny Eagle are threatened species, classed as 'Vulnerable' in South Africa (Barnes 2000), the establishment of apparently healthy, breeding populations of eagles on Karoo power lines is considered a positive by-product of the country's expanding power grid (Boshoff 1993, Anderson 2000, Jenkins et al. 2005). This operates in contrast to known negative impacts of power lines on these and other threatened birds, such as mortality in collisions with conductors or earth wires, or in electrocutions on live hardware (Lehman et al. 2007, Jenkins et al. 2010, Shaw et al. 2010, Jenkins et al. 2011, Guil et al. 2011).

Unfortunately, while the eagles have seemingly benefited from the presence of the power lines, by the late 1990s their presence on electricity pylons in the Karoo was thought to be causing substantial financial losses to the national power utility (de Goede and Jenkins 2001), which threatened to undermine the sustainability of this relationship. The apparent point of conflict was a high incidence of line faulting, or power dips or outages, recorded on Eskom's key, high-voltage transmission lines in the Karoo at this time, much of which could be sourced to the vicinity of eagle nests in the upper reaches of the pylon latticework. These 'flashovers' were thought to be caused by long 'streamers' of excrement, deposited over the conductors or onto the insulators by either the adult or nestling eagles at or in the immediate vicinity of occupied nests, resulting in an air-gap breakdown between phase and earth, which in turn produces a temporary short-circuit (van Rooyen 2001, Sundararajan et al. 2004). Generally, these incidents were not thought to directly affect the birds themselves (electrocution of eagles on such large transmission structures is very rare; Lehman et al. 2007), but occasionally flashovers resulted in eagle nests catching fire and being totally destroyed. From the power utility's perspective, by effectively interrupting critical transmission links between the major power stations in the north of the country and urban and industrial centres in the south, eagle-related line faults were proving to be extremely costly to both Eskom and the South African economy (van Rooyen et al. 2002).

In 2002, we developed a solution to this impasse, primarily by (i) determining the size and distribution of the eagle population resident on a representative sample of high voltage transmission lines in the Karoo; (ii) examining the relationship between the distribution of eagle nests and the distribution of line-faults, and (iii) if necessary, developing a management strategy which allows the continued, successful occupation of pylon nests by large eagles while reducing the putative negative effects of the eagles on the quality of power supply to financially tolerable levels. Here we describe the methodology and the efficacy of the strategy proposed to manage and alleviate the conflict between eagles and a major power utility in the Karoo.

\section{Methods}

The study was conducted in the central and south-west Karoo region of south-western South Africa (Figure I), including the entire south-central portion of the Nama Karoo biome, the eastern half of the Succulent Karoo biome, and the northern fringes of the Fynbos biome. Most of the Karoo region is used for ranching, mainly of small domestic livestock (sheep and goats), but also of various species of indigenous stock such as Ostrich Struthio camelus and springbok Antidorcas marsupialis (Milton and Dean 1996). A more detailed description of the habitat in the study area is given in Machange et al. (2005). 


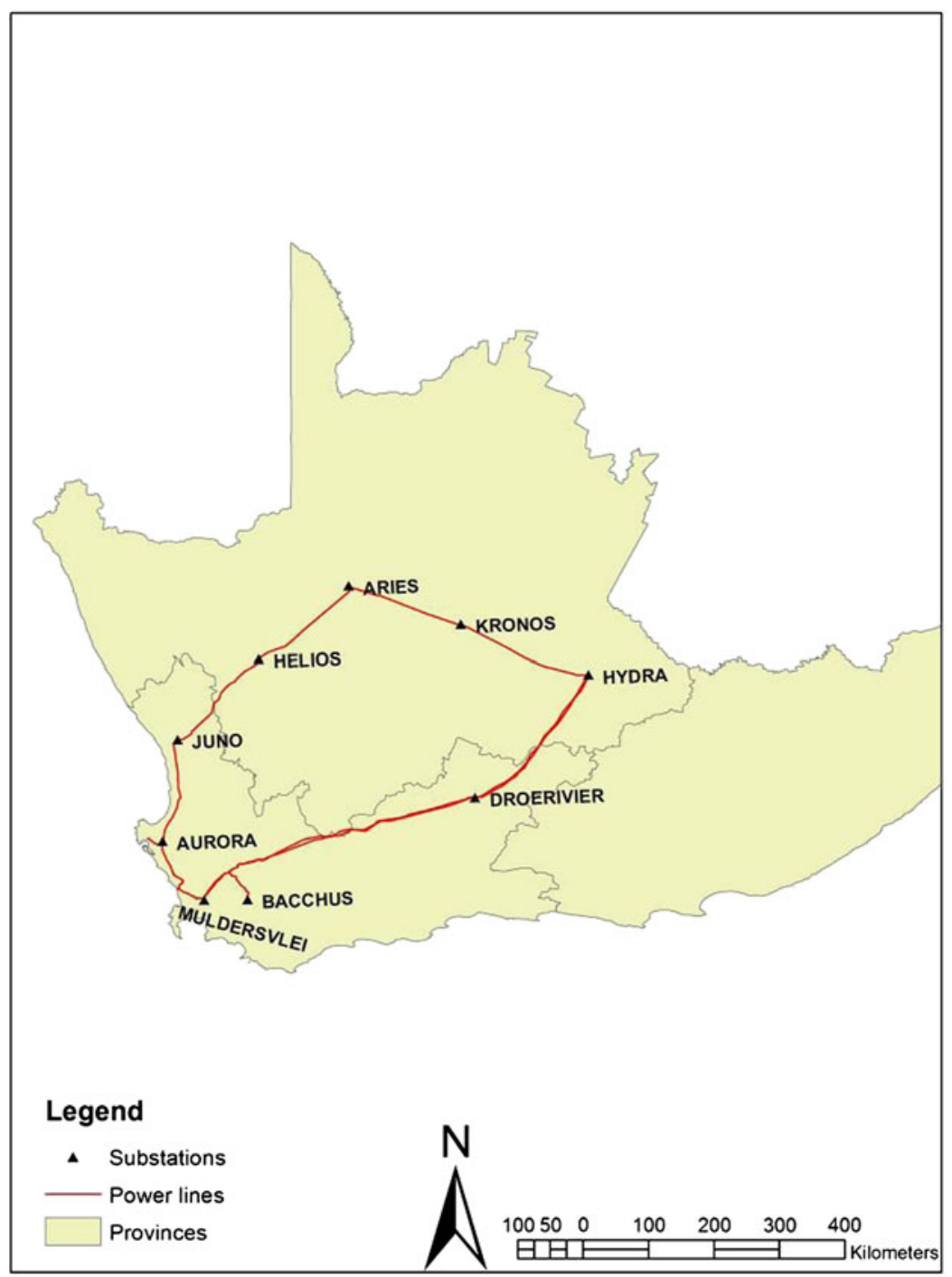

Figure 1 . The location of the study area in south-western South Africa, showing the layout of the surveyed electricity transmission pylon lines in relation to Eskom substations.

\section{The eagle population}

A sample section of about $1,400 \mathrm{~km}$ of high voltage (40okV) electricity transmission line, extending across the south-west and central Karoo (Figure I), was surveyed each year from 2002 to 2006. The total sample was made up of eight discrete sub-sections of line (two of which comprise two or three separate power lines running closely in parallel), each about $100-300 \mathrm{~km}$ in length. These were separated by and named in terms of the substations at their respective points of origin and destination (Aurora-Koeberg, Aurora-Juno, Juno-Helios, Aries-Helios, Helios-Kronos, KronosHydra, Droërivier-Hydra 1-3, and Droërivier-Muldersvlei/Bachus-Droërivier; Figure 1). The lines were surveyed from a helicopter from mid-June to early July each year, 2002-2005, and in 
mid-August 2006. The timing of these survey flights coincided roughly with the early-mid nestling stages of the eagles' breeding cycles. Each flight was done over two consecutive days, starting in, and returning to, Cape Town, in a four-seater aircraft carrying the pilot and $2-3$ observers. The helicopter was flown at about $120 \mathrm{~km}$ per hour, about $30 \mathrm{~m}$ above the tops of the surveyed power lines, and slightly off-set to the right so that the two observers on the left of the aircraft had clear views of each pylon (Malan 2009).

On the first flight in 2002, the exact location of all large eagle nests observed on the electricity pylons surveyed was recorded using a Global Positioning System (GPS) and coupled with information on observed eagle breeding activity. This initial dataset was updated on each successive survey flight. Pairs of large eagles often build more than one nest structure, and alternate between nests in successive breeding attempts (e.g. Martial Eagle territories may contain up to seven nests; Steyn 1982). Where multiple nest structures were located in short sections of pylon line (e.g. $<5 \mathrm{~km}$ apart; Boshoff 1993, Machange et al. 2005) these were considered to be alternative nests within a single eagle territory. Note that, in some instances, nests of two separate pairs located close together may have erroneously been allocated to a single territory, resulting in an underestimation of the total number of eagle territories in the study population.

The contents and surroundings of every nest surveyed were carefully noted, and used to assess the status of the population. Each identified territory was classified either as 'active' (including a nest containing fresh lining, an egg or a nestling); 'inactive but occupied' (one or a pair of adult eagles was seen, fresh whitewash and/or prey remains were noted, but no definite signs of breeding were recorded); or 'vacant' (no eagles or fresh signs of eagles seen, all nest sites looked old and degraded). While the information obtained on breeding activity can be considered absolutely accurate, the information on territory occupancy was inherently unreliable, given that eagles present on surveyed but inactive territories could easily have been overlooked. A crude measure of "apparent nest success" or breeding activity (Jehle et al. 2004, Steenhof and Newton 2007 ) in the population was achieved, based on this single aerial assessment, and expressed simply as the number or proportion of surveyed territories recorded as active each year.

In order to provide temporal context for our data on breeding activity, we also present information obtained in 1998-2001 (J. H. de Goede unpubl. data) before our study and management interventions commenced, derived from fixed-wing aerial surveys of a sub-sample of what became our actively managed population, and a one-off ground survey of the same lines, conducted in 2009 .

\section{Line faulting}

In order to determine the nature and extent of the relationship between eagles and faulting, we needed accurate information on the location of line faults to compare with the distribution of nests. Line faulting data were provided by the relevant staff at the southern and western region transmission offices of Eskom. In most cases, the fault location and timing was pinpointed by a travelling wave recorder, which measures the distance between the source of the fault and the nearest substation on the relevant line, and allows the utility to accurately determine the closest pylon to the fault source. The details of every fault are captured on a central database, as are the outcomes of subsequent field investigations done to determine causes and options for mitigation should this be required. All faults recorded on lines within the broader Karoo study area where eagles were known to occur and breed, which could not obviously be attributed to other sources - fire and associated air pollution, lightning, other birds (in particular aggregations of waterfowl) - were assumed to have been caused by eagles.

All the transmission lines included in the study featured varying proportions of three basic pylon or tower designs: 'IVI' towers (Figure 2a), in which the outer conductors are suspended vertically on single insulator strings, with the centre phase suspended by two, angled strings; 'VVV' towers (Figure $2 b$ ), in which all three conductors are suspended by two, angled insulator strings; and 'Strain' towers (Figure 2c), in which the conductors are not suspended, but are held in 

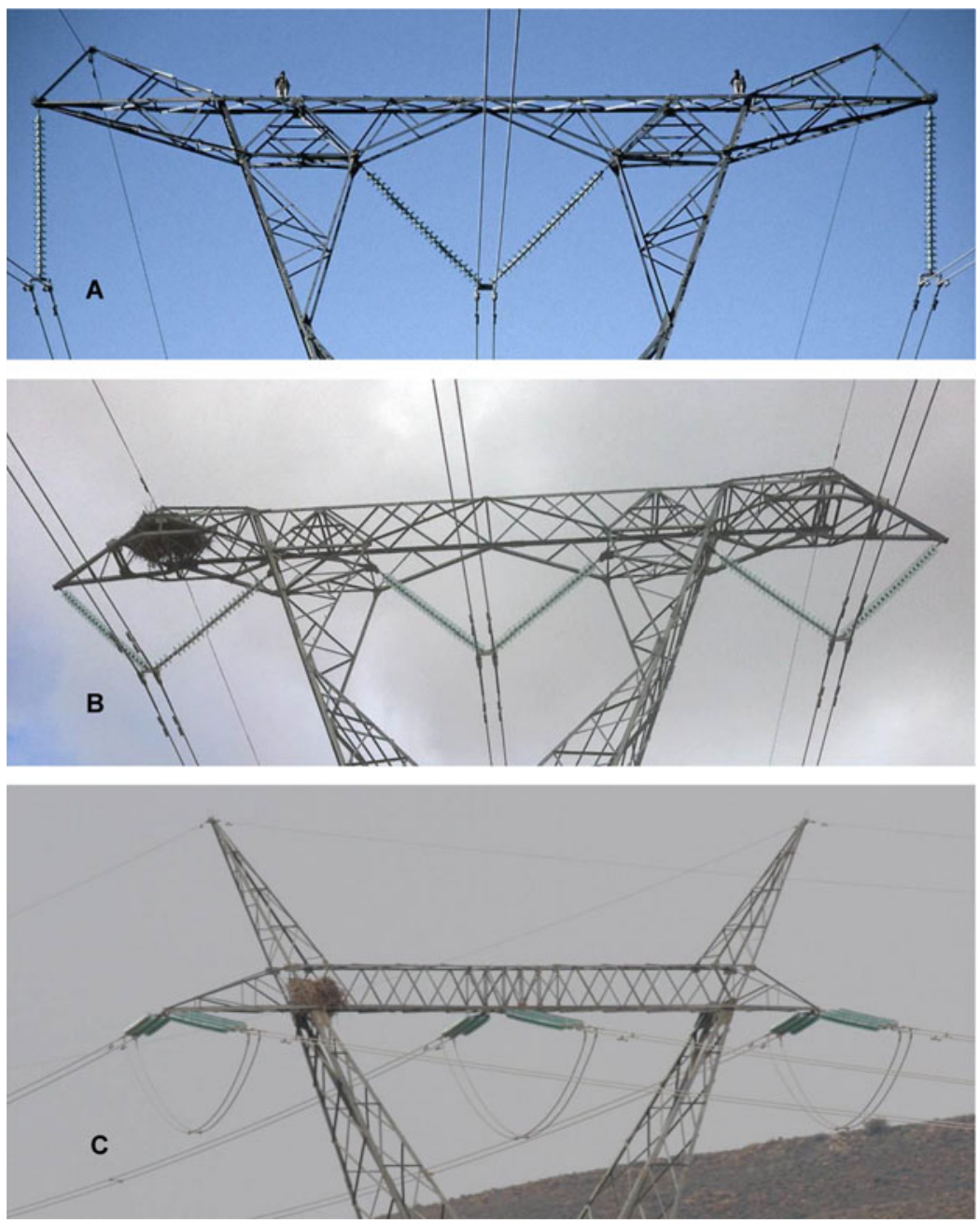

Figure 2. The three main transmission pylon configurations supporting the power lines included in this study: (a) IVI configuration, with the outer conductors suspended vertically below the cross-arm, (b) VVV configuration, with all three conductors suspended by two, angled insulator strings, and (c) Strain configuration, with all three conductors tensioned directly on to the cross-arm.

line with horizontal insulator strings. IVI towers are the least stable and tend to be used in flat landscapes, VVV towers are more stable, and used in areas of higher relief and/or wind, and Strain towers are the most stable, and used in areas of highest relief and/or wind and at the point of major changes in vertical or horizontal alignment. Given that the three tower designs feature subtly or obviously different structural latticework and conductor/insulator configurations, they were considered likely to vary in both their potential to accommodate large eagle nests, and their inherent flashover risk profiles. For example, because of differences in conductor configurations, eagles can build their nests directly above all three power phases on a VVV structure, but can only do so above the centre phase on an IVI tower, so VVV towers may have an inherently higher faulting risk than IVIs. 
We assessed the relationship between tower structure, eagle nest distribution and transmission line faults by comparing the existing data describing the ratio of eagle nests and line faults observed on each tower design (VVV, IVI, Strain and others) with the overall ratio of tower designs available on each line (determined during a helicopter survey in June 2004). Chi-squared tests were used to provide a conservative, non-parametric statistical comparison of the expected distribution of eagle nests on each line (assuming tower designs were used in proportion to their availability) and the actual distributions observed.

Early in the study, it emerged that roosting eagles were a significant source of line faulting, in addition to faulting associated with active nests. To investigate this further and to examine ways in which to reduce faulting caused by roosting birds, we collected information on eagle roost sites in 2004, mostly at territories on the Hydra-Droërivier lines. Initially, we had hoped also to test the relative efficacy of two management interventions (bird-guards and nest relocations - see below) in reducing the frequency with which eagles roost in flashover-prone areas of pylons. However, because it was not possible to fully implement our management strategy before this work was done, we were restricted to an examination of possible differences in roost site selection between eagles associated with nests located in different areas of the pylon (above or below the conductors). Hypothetically, eagles tending lower nests might roost more frequently at this level, below the conductors, indirectly reducing the likelihood of line-faulting caused by roosting birds. Eagles were observed at their roosts at last light, and again at first light the next morning to confirm that they had remained at the same roost site overnight. Observations were made using a $20-60 \mathrm{x}$ telescope from distances exceeding $1-2 \mathrm{~km}$ to ensure that eagle behaviour was not affected by observer presence (González et al. 2006).

\section{Management strategy}

Simply removing eagle nests from pylons was not considered a viable or preferred solution to the problem of eagle-related faulting given (i) the likelihood that the birds would simply recolonise the pylons (e.g. Burger and Gochfeld 2009, A.R. Jenkins pers. obs), and (ii) Eskom's stated commitment to environmental sensitivity and the conservation of threatened species. We identified two primary means by which we could feasibly manage the incidence of eagle-related faulting. Firstly, we could encourage eagles to nest below the conductors by relocating problem nests built in the upper reaches of towers to safer locations lower down (Steenhof et al. 1993). The nest relocation process we developed involves the complete removal of a known or potential problem nest from a situation in the top of a pylon, followed by reconstruction of the nest using as much of the original nest material as possible in a galvanized steel "basket", which is then hoisted and firmly affixed to the metalwork in the waist of the nest pylon, well below the conductors (Figure $S_{I}$ in the online supplementary material). Secondly, we could use obstructive perch deterrents or 'bird guards' to block high risk areas of the pylon (i.e. those situated directly above the conductors), and so discourage eagles from nesting, perching or roosting in such places (van Rooyen 2001, van Rooyen et al. 2002, Lammers and Collopy 2007, Slater and Smith 2010). The devices used were "BeeTee" bird guards, made locally from high-density polyethylene, 500-1000 mm long, with vertical rods extending to about $500 \mathrm{~mm}$ in height, and attached to the tower latticework by means of stainless steel straps.

\section{Measuring the success of management}

The success of the management strategy imposed was gauged in terms of two main criteria: a material reduction in the frequency of eagle-related line faulting, and the continued welfare of the pylon-nesting eagle population (expressed as the proportion of territories active in each season). These parameters were compared before and after intervention on a sub-set of actively managed lines, and with a sub-set of unmanaged lines available as a control. 
To evaluate the success of the management strategy, we fitted a Generalised Linear Mixed Model (GLMM) with year as a random term, and modelled the effect of pre- and post-management on flashover occurrence as a binary measure (Yes or No), with flashover occurrence set as the response variable, and management strategy as the explanatory variable. All GLMMs were carried out in $\mathrm{R}$ version 2.14.I(R Development Core Team 2011). We used the appropriate $\mathrm{R}$ function to control for the fact that each year of study had a different number of territories. The GLMM had a binomial error structure with a logit link function. Having established the relationship between flashover occurrence and management, we examined the influence of management on breeding activity (as a binary measure, Yes or No), again by means of a GLMM (with a binomial error structure with a logit link function), with breeding activity as the response variable, and management as the explanatory variable. For both these analyses we only used data from the two sets of managed lines (Droërivier-Hydra lines 1-3 and Droërivier-Muldersvlei/Bachus-Droërivier).

\section{Results}

\section{The eagle population}

Up to 96 large eagle territories were identified during the study, and up to 55 pairs of eagles actively bred in any one year (Appendix $\mathrm{S}_{1}$ in the online supplementary material). Within these territories, a maximum of 139 nest structures were present in surveyed pylons (Appendix S2), with up to four nest structures contained in a single territory. Overall, the study accumulated 357 pair-years of basic nest monitoring at eagle territories, and documented 24I breeding attempts (Appendix SI).

Martial Eagles made up the majority of eagle pairs in the study population, with up to 66 territories and 57 resident pairs, an average territory occupancy rate of $79.4 \%$ (range: $70-88 \%$, $n=5$ years), and an average of $62.8 \%$ of territorial pairs attempting to breed each year (range: $46-78 \%, n=5$ years) (Appendix $S_{1}$ ). Verreaux's Eagles were initially only found on the AriesKronos and Droërivier-Hydra lines, but colonised the Droërivier-Muldersvlei/Bachus and HydraKronos lines from 2004 and 2006 onwards respectively. Up to 13 Verreaux's Eagle territories were located on the surveyed lines, with an average of $95.0 \%$ of territories occupied (range: $87.5-100 \%$, $n=5$ years) and $86.5 \%$ of occupied territories active (range: $69.2-100 \%, n=5$ years) each year. Tawny Eagles were found only on the Hydra-Kronos and Droërivier-Hydra lines. Up to 17 Tawny Eagle territories were identified, with an average of $78.5 \%$ of territories occupied (range: $68.8-84.6 \%$, $n=5$ years) and $77.2 \%$ of occupied territories active each year (range: $69.2-100 \%, n=5$ years).

\section{Line faulting}

In $2002 / 2003,39 \%(24 / 62)$ of all faulting incidents on lines included in the study were definitely or possibly caused by eagles. Before the full instigation of the faulting management strategy in 2005 , the relationship between eagle-related line faulting and eagle nesting appeared more tenuous than expected. While there was a positive correlation between fault frequency on each line and the density of active nests (Figure 3; Spearman's $r_{s}=0.49, P>0.05, n=8$ ), at least three lines supporting quite high eagle densities experienced little if any faulting. Hence, a combined total of 47 eagle breeding attempts at 25 occupied territories on the Helios-Juno, Aries-Helios and AriesKronos lines incurred no eagle-related faults at all during 2002-2004, while 13 occupied territories and 23 breeding attempts on the Droërivier-Muldersvlei/Bachus-Droërivier lines produced a total of 24 flashovers at a rate of 3.25 faults/ Ioo km line/year (ppendix S2, Figure 3). This apparent paradox may be related to the types of structure present on each line, and the influence this may have on nest location and fault frequency. There was a preponderance of VVV towers on the Droërivier-Muldersvlei and Bacchus-Droërivier lines, contrasting with a preponderance of IVI towers on the Helios and Aries lines (Table 1). We found a weak but discernible relationship between the number of nestings in VVV towers and the frequency of eagle-related line faults 


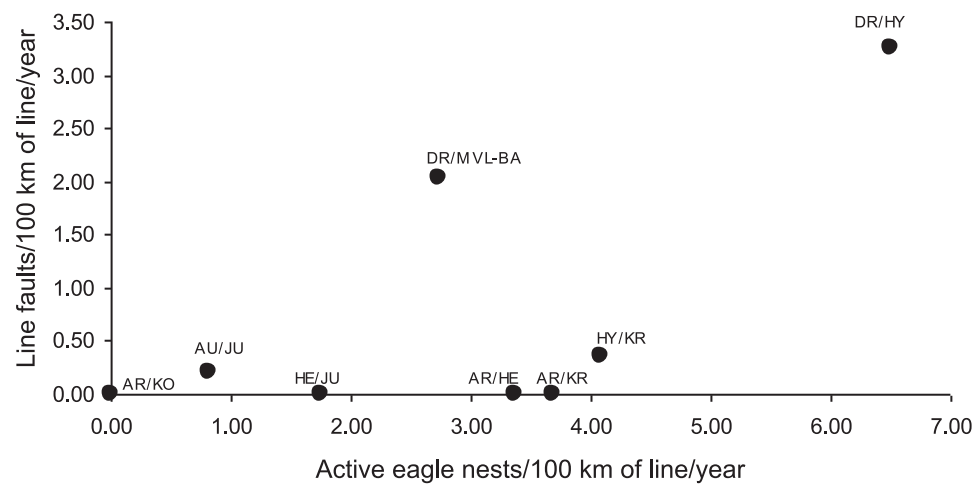

Figure 3. Eagle-related line faulting on Karoo transmission lines plotted against the density of active nests for the period 2002-2004 (pre-management).

recorded per occupied territory on each line (Table 1 ), and a strong and statistically significant preference for VVV structures as nest sites by eagles on nearly all of the lines included in the study (Table I), hence there were more flashovers on the lines with the greatest number of VVV towers.

Roosting data were collected at 1o active territories on the Hydra-Droërivier lines, two territories on the Helios-Juno line, and one territory on the Droërivier-Muldersvlei line, at eight Martial Eagle territories and five Verreaux's Eagle territories, and at eight nests situated in the top of towers and five different waist nests. In $20 \%$ of nights spent at Martial Eagle sites, and at $8 \%$ of nights at Verreaux's Eagle sites, only one roosting bird (presumably the female) was located. The second bird of the pair could have been roosting either nearby but off the pylon line, or on a distant pylon out of sight. In total, 46 eagle-nights of observation were completed in which the roost site of an individual bird could be determined with accuracy and confidence. Twenty nights were completed at Martial Eagle nests and 26 at Verreaux's Eagle nests, and 28 nights at top nests and 18 at waist nests (Appendix $\mathrm{S}_{2}$ ).

In $54 \%$ of cases, eagles roosted above the conductors, in $17 \%$ they roosted directly over the conductors, and in $15 \%$ of cases (but only at Verreaux's Eagle nests) they roosted over the conductors on VVV structures (Figure 4, Appendix S2). Martial Eagle pairs tended to roost

Table 1. Evaluation of the use of VVV pylon structures (vs other tower designs) as nest sites by large eagles in relation to their estimated availability on each of the Karoo transmission lines surveyed. Statistically significant preferences for VVV structures are denoted by ${ }^{* *}(P<0.01)$ and ${ }^{* *}(P<0.001)$.

\begin{tabular}{|c|c|c|c|c|c|c|c|}
\hline \multirow[t]{2}{*}{ Line } & \multirow{2}{*}{$\begin{array}{l}\text { Proportion } \\
\overline{\text { of VVV's }}\end{array}$} & \multirow[t]{2}{*}{$n$ Nests } & \multicolumn{2}{|c|}{$\begin{array}{l}\text { Expected Distribution } \\
\text { of Nests }\end{array}$} & \multicolumn{2}{|c|}{$\begin{array}{l}\text { Observed Distribution } \\
\text { of Nests }\end{array}$} & \multirow{2}{*}{$\begin{array}{l}\chi^{2} \text { Value } \\
(\mathrm{df}=1)\end{array}$} \\
\hline & & & on VVV's & $\begin{array}{l}\text { on Other } \\
\text { Designs }\end{array}$ & on VVV's & $\begin{array}{l}\text { on Other } \\
\text { Designs }\end{array}$ & \\
\hline Aurora-Koeberg & 0.01 & 1 & o & 1 & 1 & o & o \\
\hline Aurora-Juno & 0.07 & 4 & o & 4 & o & 4 & o \\
\hline Helios-Juno & 0.21 & 24 & 5 & 19 & 17 & 7 & $36.4^{* * *}$ \\
\hline Aries-Helios & 0.04 & 18 & 1 & 17 & 5 & 13 & $16.9^{* * *}$ \\
\hline Aries-Kronos & 0.04 & 15 & 1 & 14 & 5 & 10 & $17.1 * * *$ \\
\hline Hydra-Kronos & 0.12 & 17 & 2 & 15 & 6 & 11 & $9.1^{* *}$ \\
\hline $\begin{array}{l}\text { Hydra-Droërivier } \\
\text { 1-3 }\end{array}$ & 0.15 & 32 & 5 & 27 & 15 & 17 & $23.7^{* * *}$ \\
\hline $\begin{array}{l}\text { Droërivier-M'vlei/ } \\
\text { Bachus }\end{array}$ & 0.42 & 26 & 11 & 15 & 20 & 6 & $12.7^{* * *}$ \\
\hline
\end{tabular}


separately and further from their nests ( $0-5$ towers away) than Verreaux's Eagles ( -1 towers away), although it was notable that no bird was observed roosting further than five towers away from their nest tower. Eagles using waist nests tended to roost below the conductors more frequently than eagles using top nests (Figure 4).

\section{Management strategy}

A simple three-step management strategy was developed on the basis of our findings in the first two years of the study: i) All eagle nests on the main, problem lines - Droërivier-Hydra and DroërivierMuldersvlei/Bachus - where line faulting had been recorded, or where eagles frequently bred in the top of VVV towers, should be relocated to custom-built nest platforms positioned in the tower waist; ii) Bird-guards should be installed at all VVV towers within 5-10 towers on either side of all nests on the Droërivier-Hydra and Droërivier-Muldersvlei/Bachus lines; iii) Annual monitoring of eagle nests on all lines in the study area - preferably by means of a mid-year helicopter survey - should be continued, in order to measure the effects of the implementation of management recommendations on the stability and productivity of the eagle population.

The strategy had only been partly implemented by the end of the study in 2006. Seventeen $(53 \%)$ of 32 recommended nest relocations had been effected (starting in 2003, but mostly done in 2004-2005), and while the stipulated bird guard scheme was largely completed in early 2005, this was done with numerous errors and omissions attributable to poor communication between the power utility and their selected contractors.

\section{Measuring the success of management}

Line faulting for all lines combined in 2005-2006 was reduced by $62 \%$ overall (relative to the average for 2002-2004), and by $68 \%$ from the preceding year - 2004 yielded 19 faults, with only six faults in 2005 (Figure 5, Appendix $\mathrm{S}_{3}$ ). The managed lines showed a $74 \%$ reduction in faulting overall, and a $78 \%$ reduction from 2004 to 2005 . This substantial decrease in flashover occurrence, coincident with the management of problem nests was statistically significant on both of the managed lines (Bachus- Droërivier/Droërivier-Muldersvlei lines, $\mathrm{F}_{1,129}=3.94, P=0.008$; Hydra lines, $\mathrm{F}_{1,159}=3.80, P=0.005$.

Although there was a steady and discernible decrease in the proportion of eagle territories attempting to breed in the managed population from a peak in 2002 (Figure 5), this decrease was

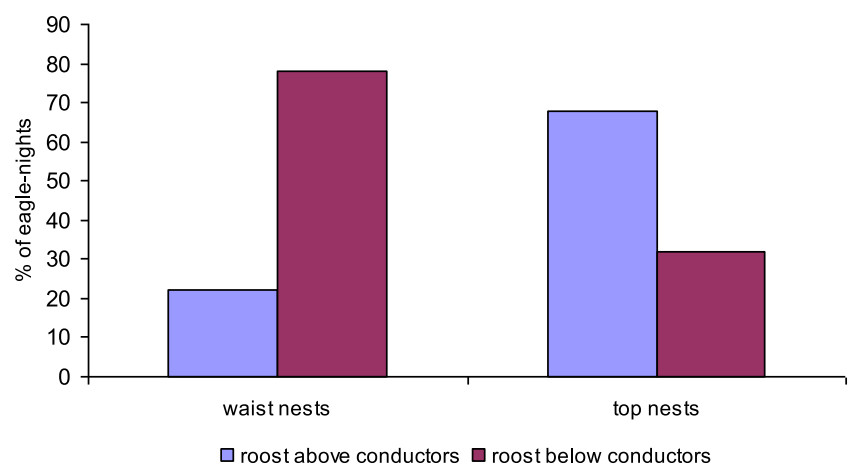

Figure 4. The relative frequency with which large eagles were observed roosting above vs below the transmission line conductors in relation to nest position. A significantly greater proportion of eagles with nests in the pylon waist roosted below the conductors (Fisher Exact Test, $P=0.006$ ) than those with nests on top of pylons. 


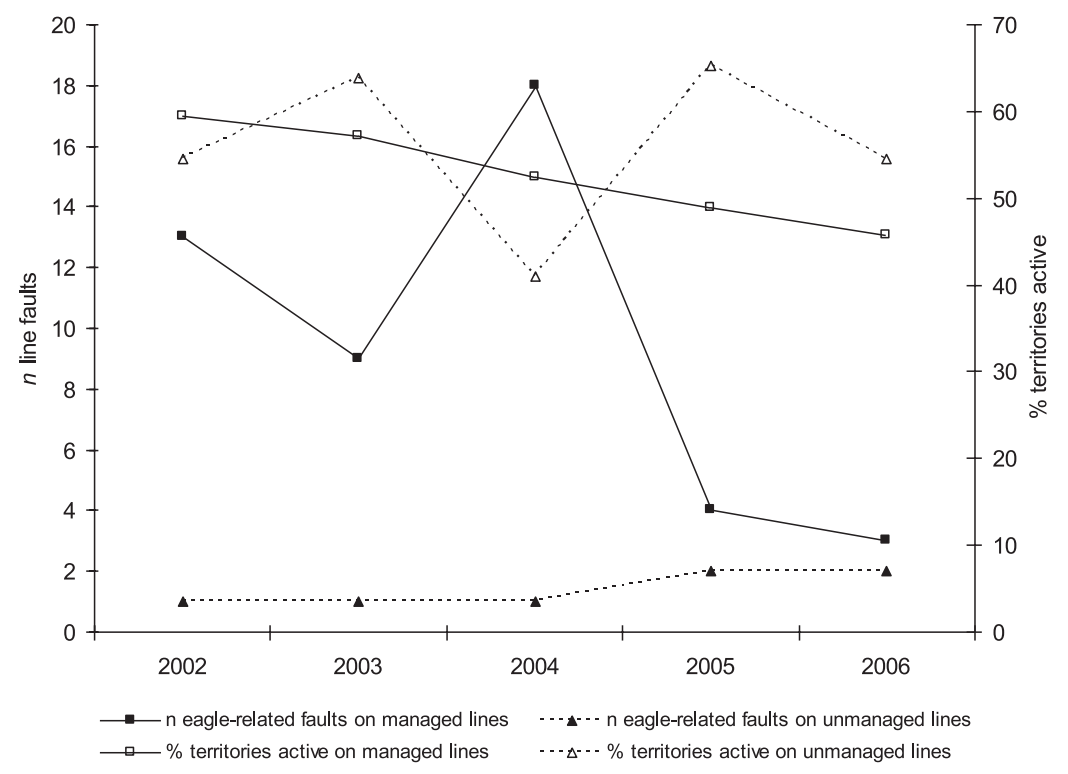

Figure 5. Eagle-related line faulting and eagle breeding activity in each year of the study for managed (2005-2006 only) and unmanaged lines.

not statistically significant on either of the two managed lines (Bachus- Droërivier/DroërivierMuldersvlei lines, $\mathrm{F}_{1,129}=3.94, P=0.243$; Hydra lines, $\mathrm{F}_{1,159}=3.80 \mathrm{P}=0.20$ ), and fell within the range of inter-annual fluctuations in breeding activity for this population over a longer monitored period (Figure 6; J. H. de Goede unpubl. data). Overall, there was little to suggest a meaningful reduction in breeding activity attributable to any of the management actions used.

This said, there was some delay in the acceptance of artificial nest platforms, with marked differences in adaptability between the three species. Of nine Martial Eagle territories in which nests were relocated to platforms, five pairs $(55.6 \%)$ subsequently bred in those platforms during the study period, and one pair immediately rebuilt their pylon-top nest and bred in it in the same year that it was relocated just before the breeding season. All of three Verreaux's Eagle pairs also readily attempted to breed in relocated nests, while the single Tawny Eagle nest moved on to a nest platform was not subsequently used.

\section{Discussion}

Breeding frequency figures for all three species in the study area (Appendices $\mathrm{S}_{1}$ and $\mathrm{S}_{2}$ ) are comparable with, or exceed, those recorded for the same species in other parts of southern Africa (e.g. Tarboton and Allan 1984, Hustler and Howells 1987, Gargett 1977, 1990, Brown 1991, Davies 1990, Herholdt et al. 1996, Herholdt and Kemp 1997), suggesting that these are generally healthy populations of considerable conservation value. Numbers of Tawny and Verreaux's Eagles nesting on Eskom power lines may be relatively small, the former because it occurs only peripherally in the open Karoo where alternative nesting substrates (large trees) are all but absent (Simmons 2005a), and the latter because colonisation of these structures is probably relatively recent. However, there is evidence to suggest that the pylon-nesting population of Verreaux's Eagles may be expanding. Certainly, the pairs included in this study were particularly productive and could form the nucleus of such a process, and numbers of Verreaux's Eagles increased from seven to 13 territories over the five years of the study, spreading from two to four of the surveyed lines (Appendix SI). 


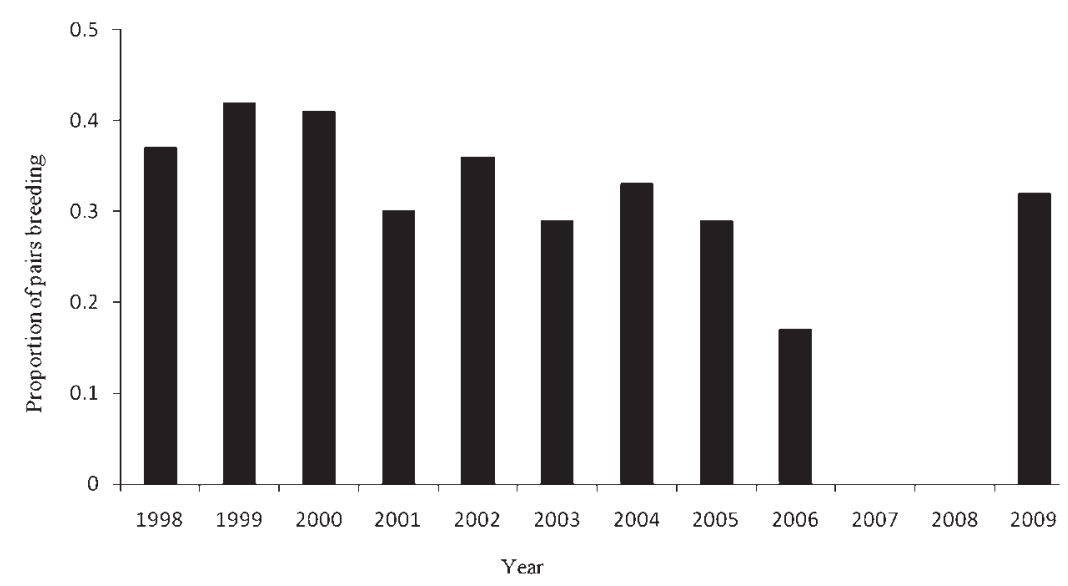

Figure 6. The proportion of surveyed eagle pairs actively breeding in each year on the three sets of managed power lines. Note: the lines were not surveyed in 2007 and 2008.

The Martial Eagle numbers documented here of $>6$ o breeding pairs are of both national and regional significance, and possibly represent the most substantial population of this threatened species in South Africa outside of formally protected areas (Barnes 2000, Machange et al. 2005, Simmons 2005c). Given that similar densities of this species may well obtain on other high voltage lines in the Karoo not covered by this study, Eskom power lines could accommodate in excess of 10\% of South Africa's total population of Martial Eagles (Barnes 2000).

Although an association was found between fault frequency and the density of active nests in most of the power lines as expected (e.g. Sundararajan et al. 2004), the virtual absence of faults on power lines with substantial eagle populations leads us to the speculate that there are other faultcausing factors which are not yet understood. We suspect that these factors may include aspects of tower design (Prather and Messmer 2010), and prevailing microclimates around the affected towers at critical times of day (Jenkins et al. 2005). This aspect of the biology and mechanics of line faulting clearly requires more research.

Nest relocation proved to be a useful proactive measure, which can be used effectively to reduce line fault frequency at large raptor nests where circumstances are known or considered likely to produce flashovers (Steenhof et al. 1993, Sundararajan et al. 2004). However, note that nest relocations (i) are not a complete solution (some territories with relocated nests continued to be the source of faulting post-management), and should be undertaken in combination with other interventions (see below); (ii) may result in a short-term drop in eagle productivity, particularly as shy species or populations acclimatise to modified nesting arrangements, but that this should not have any long-term significance, and (iii) should always be done with caution and with expert supervision, and with due consideration of any possible risk to the eagles in positioning their nests closer to the ground and thus facilitating persecution by landowners or increasing the impact of disturbance.

This study found that eagle roost site selection and roosting behaviour on high voltage power lines is at least as important in affecting faulting patterns and frequencies as the distribution of nests, and that management and reduction of eagle-related line faulting can only be achieved by a combination of actions that (i) encourage eagles to nest below the conducting elements of the line, and (ii) discourage eagles from roosting or perching above the conductors. The latter was achieved by means of a large-scale bird-guard installation scheme (e.g. Sundararajan et al. 2004, Slater and Smith 2010). The considerable costs of such a scheme were reduced by first determining the distribution of frequently occupied eagle territories, and by refining understanding of line faulting in relation to factors such as nest location and tower design. In this 
way, it was possible to produce an optimised bird-guard scheme that targets only occupied eagle territories and susceptible tower designs. Clearly, preventative costs are cheaper than the cost of outages and repairs to damaged structures (Sundararajan et al. 2004). In this instance, the full research and intervention budget for this project over five years totalled around US\$120,000, while the amount the company saved by reducing eagle-related outages by $>75 \%$ was in the region of US\$260,000, yielding a net saving of about US\$140,000, in addition to a positive conservation outcome.

It is important to note here that the recommended management strategy stemming from this study was only partially implemented, and that after the application of management measures was stopped (due to the termination of funding for this work), line faulting started to recur, most likely in association with unmanaged and/or new nests. Hence, while the initiative was generally a success, this achievement was compromised by the power utility's reluctance to commit fully to the intervention scheme, and abbreviated by its failure to follow through with an ongoing survey and maintenance regime, that was recognised as essential to the long-term efficacy of the project.

\section{Conclusions}

A number of important conclusions emerge from this study. For example, medium and highvoltage power lines can support breeding populations of large raptors of considerable conservation value (Boshoff 1993, Steenhof et al. 1993, Prather and Messmer 2010). In addition, our results suggest that without active management, these birds may be the source of commercially significant levels of line-faulting. Such line-faulting may be only partly explained by the distribution and density of active nests (with the remainder attributed to roosting adults), and both nest placement and faulting frequency may be strongly influenced by tower or pylon design. Importantly, the combined strategy of nest relocation and the installation of bird guards can be very effective in reducing eagle-related faulting, without any obvious, lasting ill effects on the eagle population under management. In order for such a strategy to be successful in the long term, the power utility must commit to a level of ongoing annual monitoring and maintenance, in order to effectively adjust, expand or redistribute the various interventions as the distribution of problem nests changes over time.

\section{Supplementary Material}

The online supplementary materials for this article can be found at journals.cambridge.org/bci

\section{Acknowledgements}

This work was funded by Eskom's Research \& Development Division; we thank Michael D. Michael for his support as well as Eskom staff and the landowners of the Karoo for their cooperation. Particular thanks to Hein Swart of the Eskom live-line team for his help in putting up the eagle nest platforms. Also, sincere thanks to Chris van Rooyen and Jon Smallie for their respective roles in promoting, developing and supporting this research.

\section{References}

Anderson, M. D. (2000) Raptor conservation in the Northern Cape Province, South Africa. Ostrich 71: 25-32.

Barnes, K. N. (2000) Martial Eagle. Pp. 83-85 in K. N. Barnes, ed. The Eskom Red Data Book of birds of South Africa, Lesotho and
Swaziland. Cape Town: BirdLife South Africa.

Boshoff, A. F. (1993) Density, breeding performance and stability of Martial Eagles Polemaetus bellicosus breeding on electricity pylons in the Nama-Karoo, South Africa. 
Pp. 95-104 in R. T. Wilson, ed. Proceedings of the Eighth Pan-African Ornithological Congress. Tervuren: Musee Royal de I'Afrique Centrale.

Brown, C. J. (1991) Declining Martial Polemaetus bellicosus and Tawny Aquila rapax Eagle populations and causes of mortality on farmlands in central Namibia. Biol. Conserv. 56: 49-62.

Burger, J. and Gochfeld, M. (2009) Exotic monk parakeets (Myiopsitta monachus) in New Jersey: nest site selection, rebuilding following removal, and their urban wildlife appeal. Urban Ecosyst. 12: 185-196.

Carrete, M., Sánchez-Zapata, J. A., Martínez, J. E., Sánchez, M. A. and Calvo, J. F. (2002) Factors influencing the decline of a Bonelli's eagle Hieraaetus fasciatus population in southeastern Spain: demography, habitat or competition? Biodivers. Conserv. 11: 975-985.

Davies, R. A. G. (1990) Black Eagle Aquila verreauxi predation on Rock Hyrax Procavia capensis and other prey in the Karoo. PhD thesis. University of Pretoria, Pretoria.

Dean, W. R. J. (1975) Martial Eagles nesting on high tension pylons. Ostrich 46: 116-117.

De Goede, K. and Jenkins, A. (2001) Electric eagles of the Karoo. Africa: Birds \& Birding 6: 62-67.

Del Hoyo, J., Elliott, A. and Sargatal, J., eds. (1994) Handbook of the birds of the world. Volume 2, New World vultures to guineafowl. Barcelona: Lynx Edicions.

Ferguson-Lees, J. and Christie, D. A. (2001) Raptors of the world. London: Christopher Helm.

Gargett, V. (1977) A 13-year population study of the Black Eagles in the Matopos, Rhodesia, 1964-1976. Ostrich 48: 17-27.

Gargett, V. (1990) The Black Eagle: a study. Randburg, South Africa: Acorn Books.

González, L. M., Arroyo, B. E., Margalida, A., Oria, J. and Sánchez, R. (2006) Effect of human activities on behaviour and success of breeding Spanish imperial eagles Aquila adalberti. Anim. Conserv. 9: 85-93.

González, L. M., Margalida, A., Mañosa, S., Sánchez, R., Oria, R., Molina, J. I., Aranda, A., Caldera, J. and Prada, L. (2007) Causes and spatio-temporal variations of non-natural mortality in the Vulnerable Spanish Imperial
Eagle (Aquila adalberti) during a recovery period. Oryx 41: 495-502.

Guil, F., Fernández-Olalla, M., Moreno-Opo, R., Mosqueda, I., Goméz, M. E., Aranda, A., Arredondo, Á., Guzmán, J., Oria, J., González, L. M. and Margalida, A. (2011) Minimising mortality in endangered raptors due to power lines: the importance of spatial aggregation to optimize the application of mitigation measures. PLOS ONE 6: e28212.

Herholdt, J. J., Kemp, A. C. and Du Plessis, D. (1996) Aspects of the breeding status and ecology of the Bateleur and Tawny Eagle in the Kalahari Gemsbok National Park, South Africa. Ostrich 67: 126-137.

Herholdt, J. J. and Kemp, A. C. (1997) Breeding status and ecology of the Martial Eagle in the Kalahari Gemsbok National Park, South Africa. Ostrich 68: 80-85.

Herremans, M. and Herremans-Tonnoeyr, D. (2000) Land use and the conservation status of raptors in Botswana. Biol. Conserv. 94: 31-41.

Hustler, K. and Howells, W. W. (1987) Breeding periodicity, productivity and conservation of the Martial Eagle. Ostrich 58: 135-138.

Jehle, G., Yackel Adams, A. A., Savidge, J. A. and Skagen, S. K. (2004) Nest survival estimation; A review of alternatives to the Mayfield estimator. Condor: 106: 472-484.

Jenkins, A. R., van Rooyen, C. S., de Goede, J. H. and Matshikiza, M. T. (2005) Managing raptor interactions with transmission lines in South Africa. Proceedings of the IASTAD European Conference on Power and Energy Systems. Calgary, Canada: ACTA Press. Track 468-816.

Jenkins, A. R., Smallie, J. J. and Diamond, M. (2010) Avian collisions with power lines: a global review of causes and mitigation with a South African perspective. Bird Conserv. Internatn. 20: 263-278.

Jenkins, A. R., Shaw, J. M., Smallie, J. J., Gibbons, B., Visagie, R. and Ryan, P. G. (2011) Estimating the impacts of power line collisions on Ludwig's Bustards Neotis ludwigii. Bird Conserv. Internatn. 21: 303-310.

Lammers, W. M. and Collopy, M. W. (2007) Effectiveness of avian predator perch deterrents on electric transmission lines. J. Wildl. Manage. 71: 2752-2758. 
Lehman, R. N., Kennedy, P. L. and Savidge, J. A. (2007) The state of the art in raptor electrocution research: A global review. Biol. Conserv.: 136 159-174.

Machange, R. W., Jenkins, A. R. and Navarro, R. A. (2005) Eagles as indicators of ecosystem health: is the distribution of Martial Eagle nests in the Karoo, South Africa, influenced by variation in land-use and rangeland quality? J. Arid Environ. 63: 223-243.

Malan, G. (2009) Raptor survey and monitoringA field guide for African birds of prey. Pretoria, South Afica: Briza.

Marzluff, J. M., Bowman, R. and Donnelly, R., eds. (2001) Avian ecology and conservation in an urbanizing world. Dordrecht, The Netherlands: Kluwer Academic.

McKinney, M. L. (2002) Urbanization, biodiversity, and conservation. Bioscience 52: 883-89o.

Milton, S. J. and Dean, W. R. (1996) Karoo Veld: ecology and management. Pretoria, South Africa: Agricultural Research Council.

Newton, I. (1979) Population ecology of raptors. Calton, UK: T \& AD Poyser.

Prather, P. R. and Messmer, T. A. (2010) Raptor and corvid response to power distribution line perch deterrents in Utah. J. Wildl. Manage. 74: 796-80o.

$\mathrm{R}$ Development Core Team (2011) R: A Language and Environment for statistical computing. Vienna, Austria: R Foundation for Statistical Computing. URL http:// www.R-project.org.ISBN 3-900051-07-0.

Rutz, C. (2008) The establishment of an urban bird population. J. Anim. Ecol. 77: 1008-1019.

Ryabatsev, V. V. and Katzner, T. E. (2007) Severe declines of Eastern Imperial Eagle Aquila heliaca populations in the Baikal region, Russia: a modern and historical perspective. Bird Conserv. Internatn. 17: 197-209.

Shaw, J. M., Jenkins, A. R., Ryan, P. G. and Smallie, J. J. (2010) A preliminary survey of avian mortality on power lines in the Overberg, South Africa. Ostrich 81: 109-113.

Simmons, R. E. (2005a) Tawny Eagle. In: P. A. R. Hockey, W. R. J. Dean, and P. G. Ryan, eds. Roberts birds of southern Africa, VII. Cape Town, South Africa: John Voelcker Bird Book Fund.
Simmons, R. E. (2005b) Verreaux's Eagle. In: P. A. R. Hockey, W. R. J. Dean, and P. G. Ryan, eds. Roberts birds of southern Africa, VII. Cape Town, South Africa: John Voelcker Bird Book Fund.

Simmons, R. E. (2005c) Martial Eagle. In: P.A. R. Hockey, W. R. J. Dean, and P. G. Ryan, eds. Roberts birds of southern Africa, VII. Cape Town, South Africa: John Voelcker Bird Book Fund.

Slater, S. J. and Smith, J. P. (2010) Effectiveness of raptor perch deterrents on an electrical transmission line in southwestern Wyoming. J. Wildl. Manage. 74: 1080-1088.

Steenhof, K., Kochert, M. N. and Roppe, J. A. (1993) Nesting by raptors and common ravens on electrical transmission line towers. J. Wildl. Manage. 57: 271-281.

Steenhof, K. and Newton, I. (2007) Assessing nesting success and productivity. In: D. M. Bird and K. L. Bildstein, eds. Raptor research and management techniques. Surrey, Canada: Hancock House.

Steyn, P. (1982) Birds of prey of southern Africa. Cape Town, South Africa: David Philip.

Sundararajan, R., Burnham, J., Carlton, R., Cherney, A. R., Couret, G., Eldridge, K. T., Farzaneh, M., Frazier, S. D., Gorur, R. S., Harness, R., Shaffner, D., Siegel, S. and Varner, J. (2004) Preventive measures to reduce bird related power outages-Part II: Streamer and contamination. IEEE Transactions on Power Delivery 19: 1848-1853

Tarboton, W. and Allan, D. (1984) Status and conservation of birds of prey in the Transvaal. Transvaal Mus. Monogr. 3: 1-115.

Thiollay, J-M. (2007) Raptor population decline in West Africa. Ostrich 78: 405-413.

Van Rooyen, C. (2001) Line management: Eskom's National Bird Guard Project. Africa: Birds \& Birding 6: 12-13.

Van Rooyen, C, Vosloo, H. and Harness, R. (2002) Eliminating bird streamers as a cause of faulting on transmission lines, South Africa. Colorado Springs, Colorado: IEE $4^{6^{\text {th }}}$ Rural Electric Power Conferences.

Virani, M. and Watson, R. T. (1998) Raptors in the East African tropics and Western Indian Ocean islands: state of ecological knowledge and conservation status. J. Raptor Res. 32: 28-39. 
Whitfield, D. P., Fielding, A. H., Mcleod, D.

R. A., Morton K., Stirling-Aird, P. and

Eaton, M. A. (2007) Factors constraining the distribution of Golden Eagles Aquila chrysaetos in Scotland. Bird Study 54: 199-211.

\section{ANDREW R. JENKINS*}

Percy FitzPatrick Institute of African Ornithology, University of Cape Town, Rondebosch 7701, South Africa.

Current address: Animal Demography Unit, University of Cape Town, Rondebosch 7701, South Africa.

\section{KOOS H. DE GOEDE}

Birds of Prey Programme, Endangered Wildlife Trust, Private Bag X11, Parkview 2122, South Africa.

\section{LOVELATER SEBELE}

Avisense Consulting, 5 Osmond Close, Simon's Town 7975, South Africa.

\section{MEGAN DIAMOND}

Wildlife \& Energy Programme, Endangered Wildlife Trust, Private Bag X11, Parkview 2122, South Africa.

*Author for correspondence; email: andrew@avisense.co.za

Received 23 March 2012; revision accepted 30 January 2013 